\title{
FORMULASI STRATEGI MAKASSAR NEW PORT DAN PELABUHAN BITUNG SEBAGAI INTERNATIONAL HUB PORT
}

\section{FORMULATION OF MAKASSAR STRATEGY NEW PORT AND PORT BITUNG AS INTERNATIONAL HUB PORT}

\author{
Debby Duakajui \\ Mahasiswa Magister Manajemen Fakultas Ekonomi Unviersitas Hasanuddin \\ Email: debbyduakaju@gmail.com \\ Abd. Rahman Kadir \\ Dosen Magister Manajemen Fakultas Ekonomi Universitas Hasanuddin \\ Email: rahmankadir80@yahoo.com

\section{H. Jusni} \\ Dosen Magister Manajemen Fakultas Ekonomi Universitas Hasanuddin \\ Email: jusni-mju@yahoo.co.id
}

\begin{abstract}
Abstrak: Industri kepelabuhanan di Indonesia lebih kompleks dibandingkan pelabuhan luar negeri, mengingat Indonesia sebagai negara kepulauan yang wilayahnya lebih banyak lautan dibandingkan daratan. Penelitian ini bertujuan untuk merumuskan formulasi strategi yang harus diterapkan oleh Makassar New Port dan Pelabuhan Bitung untuk menjadi International Hub Port. Tujuan berikutnya mengidentifikasi pelabuhan mana yang harus diprioritaskan menjadi International Hub Port berdasarkan strategi yang paling efektif dan profitabel. Penelitian ini termasuk jenis penelitian penjelasan (explanatory research) berupa penelitian terapan (applied) yang bersifat dekriptif (penjelasan tanpa adanya uji-hipotesis) dengan menggunakan pendekatan kualitatif dengan fokus analisa menyusun alternatif strategi dalam perubahan lingkungan perusahaan dan alternatif strategi. Lokasi atau tempat penelitian adalah kantor cabang dan kantor pusat dari PT Pelabuhan Indonesia IV (persero) yang berkedudukan di Kota Bitung dan Kota Makassar. Data yang dikumpulkan mencakup data primer dan data sekunder. Teknik analisis dalam penelitian ini berupa analisis IFAS (Internal Factors Analysis Summary) dan EFAS (External Factors Analysis Summary), analisis SWOT (Strengths Weaknesses Opportunities Threats), Analisis Boston Consulting Group, Analisis QSPM, dan analytical hierarchy process. Hasil penelitian menunjukkan bahwa strategi yang layak diterapkan pelabuhan makassar yaitu melakukan koordinasi dengan stakeholder termasuk pemerintah, asosiasi dalam bidang konektivity baik sebagai transhipment maupun jalur baru dalam hal distribusi dan konsolidasi potensial komoditi. Strategi yang tepat bagi Pelabuhan Bitung untuk menjadi International Hub Port dengan menerapkan strategi pada kuadran pertama melalui pengoptimalan keunggulan yang dimiliki dan dukungan pemerintah, dan dengan melakukan pengembangan fasilitas dan pemetaan peluang bisnis sebagai pusat konsolidasi barang di Indonesia Bagian Timur. Hasil analisis AHP menunjukkan bahwa Makassar New Port harus diprioritaskan menjadi International Hub Port berdasarkan kajian berbagai alat analisis dengan pertimbangan berbagai kriteria sebagaimana yang terdapat dalam Keputusan Menteri Perhubungan KM 53 tahun 2003 tentang tatana kepelabuhanan nasional.
\end{abstract}

Kata kunci: International Hub Port, Pelindo IV, strategi, dan AHP

Abstract: The port industry in Indonesia is more complex than the foreign port, considering Indonesia as an archipelagic country whose territory is more ocean than land. This study aims to 


\section{Jurnal Bisnis Manajemen dan Informatika}

formulate a competitiveness strategy that must be applied by Makassar New Port and Bitung Port to become International Hub Port. The next destination identifies which ports should be prioritized to become the International Hub Port based on the most effective and profitable strategies. This research includes explanatory research in the form of applied research that is descriptive (explanation without any hypothesis) by using qualitative approach with focus of analysis to arrange alternative strategy in changing company environment and alternative strategy. Location or place of research is the head office of PT Pelabuhan Indonesia IV (Persero) based in Makassar City. The data collected includes primary and secondary data. Analytical techniques in this research are analysis of IFAS (Internal Factors Analysis Summary) and EFAS (External Factors Analysis Summary), SWOT analysis (Strengths Weaknesses Opportunities Threats), Boston Consulting Group Analysis, QSPM Analysis, and analytical hierarchy process.The result of the research indicates that the appropriate strategy to be implemented by Makassar port is to maximize the infrastructure and superstructure of the port, to prioritize excellent service, and to adopt information technology and empower human resources. The right strategy for Bitung Port is to become an International Hub Port by implementing strategies in the first quadrant through optimizing its own advantages and government support, and increasing customer value proposition. The result of AHP analysis shows that Bitung Port should be prioritized to become International Hub Port based on analysis of various analytical tools with consideration of various criteria such as port location, pond depth, modern equipment, harbor environment, and tariff.

Keywords: International Hub Port, Pelindo IV, strategy, and AHP

\section{PENDAHULUAN}

Pada era tahun 2000-an, publik menilai berbagai persoalan pelabuhan muncul dengan setidaknya empat persoalan utama. Kendala pertama adalah keterbatasan sumber modal pengelola pelabuhan dan tidak terbukanya pengelolaan pelabuhan sehingga sulit operator asing untuk masuk dalam membangun dan mengelola pelabuhan di Indonesia, kedua adalah munculnya berbagai persoalan terkait bottle-necking akibat keterbatasan infrastruktur dan suprastruktur jasa kepelabuhanan akibat keterbatasan badan usaha milik negara yaitu PT Pelabuhan Indonesia (selanjutnya disingkat PT. Pelindo) untuk melaksanakan investasi, ketiga masih terdapat tumpang-tindihnya adanya fungsi regulator dan operator jasa kepelabuhanan yang dilaksanakan oleh PT. Pelindo dan terjadinya monopoli pelayanan jasa kepelabuhanan serta problem lainnya yaitu keterbatasan sumber pendanaan negara dalam mendanai proses penyediaan pelabuhan-pelabuhan baru Indonesia melalui APBN.

Industri kepelabuhanan di Indonesia lebih kompleks dibandingkan pelabuhan luar negeri, mengingat Indonesia sebagai negara kepulauan yang wilayahnya lebih banyak lautan dibandingkan daratan. Pelabuhan-pelabuhan di Indonesia pada umumnya masih dalam kondisi buruk disebabkan oleh rendahnya infrastruktur, fasilitas, finansial, dan lainnya, sehingga biaya logistik di Indonesia masih mahal dibandingkan dengan negara tetangga.

Menghadapi permasalahan tersebut maka pada tahun 2008, Pemerintah melakukan transformasi pengelolaan pelabuhan dengan mengeluarkan Undang-Undang Nomor 17 Tahun 2008 tentang Pelayaran sebagai pengganti Undang-Undang Nomor 21 Tahun 1992 tentang 
Pelayaran yang berlaku secara efektif sejak tanggal 7 Mei 2011 dimana membuka peluang bagi swasta di sektor kepelabuhanan serta memisahkan fungsi regulator dan operator dengan tujuan untuk mendukung terciptanya lingkungan layanan pelabuhan yang kompetitif di Indonesia serta mendukung pengembangan dan pembangunan pelabuhan untuk memperkuat posisi bangsa Indonesia sebagai negara maritim.

Dalam Undang-Undang Nomor 17 Tahun 2008 tersebut Pemerintah mempunyai kewajiban untuk menyediakan lokasi dan lahan yang nantinya akan dikerjasamakan dengan BUP (Badan Usaha Pelabuhan) melalui konsesi dan akan dikembalikan kepada Negara setelah jangka waktu kerjasama telah berakhir. Undang - undang tersebut juga mengatur tentang pengelolaan pelabuhan umum secara komersial yang selama ini dilaksanakan oleh PT Pelindo dimana sampai saat ini masih terjadi perdebatan terkait dengan penyerahan pelabuhan eksisting yang selama ini telah dikelola oleh PT. Pelindo kepada Negara. Namun dengan telah efektifnya Undang-Undang Nomor 17 Tahun 2008, PT. Pelindo segera berbenah diri dan tidak tinggal diam menghadapi kondisi tersebut.

PT Pelabuhan Indonesia IV (Persero) berupaya memanfaatkan peluang dalam rangka peningkatan kinerja korporasi. Salah satunya adalah eksekusi pembangunan Makassar New Port sebagai gerbang utama percepatan pembangunan Kawasan Timur Indonesia khusunya wilayah Makassar. PT Pelabuhan Indonesia IV menargetkan Makassar New Port (MNP) dapat mengakomodir tingkat arus peti kemas dalam jangka panjang hingga tahun 2050 . Pertumbuhan ekonomi di Kota Makassar pada khususnya maupun Indonesia timur pada umumnya akan memicu peningkatan arus peti kemas maupun barang untuk memenuhi kebutuhan permintaan yang terus meningkat seiring dengan pertumbuhan penduduk.

Makassar New Port dibangun karena peran Makassar yang sangat strategis sebagai pelabuhan internasioanl karena dilalui oleh Alur Laut Kepulauan Indonesia (“ALKI”) II, serta terletak tegak lurus dengan beberapa negara tujuan eksport hasil pertanian dan tambang dari Indonesia Timur yaitu Tiongkok, Jepang, Hong Kong dan Korea. Sehingga pengembangan pelabuhan Makassar akan sangat penting untuk mendukung dan menstimulasi kegiatan eksport import di Kawasan Timur Indonesia dan mengefisienkan biaya ekspor yang selama ini dilakukan melalui Tanjung Priok dan Tanjung Perak.

Dengan pertimbangan peningkatan yang telah dicapai dan mengantisipasi peningkatan kunjungan kapal dan arus barang yang lebih pesat pada masa yang akan datang, maka pelabuhan Makassar akan dikembangkan ke arah utara secara bertahap, agar pelabuhan Makassar benar-benar dapat menjadi pusat konsolidasi untuk barang-barang ekspor dan pusat 


\section{Jurnal Bisnis Manajemen dan Informatika}

distribusi untuk barang-barang impor, sehingga pelabuhan Makassar benar-benar sebagai pintu gerbang perekonomian dan ekspor/impor di Kawasan Timur Indonesia yang kompetitif.

Perencanaan Makassar New Port sebagai pelabuhan internasional di masa depan harus menghadapi tantangan besar berupa regulasi pemerintah yang menyatakan bahwa Pelabuhan Bitung akan diwujudkan sebagai International Hub Sea Port (IHP) berdasarkan Perpres Nomor 26/2012 tentang cetak biru kebijakan pembangunan sistem logistik nasional. Pelabuhan Bitung dipilih sebagai Pelabuhan Hub Internasional di Kawasan Timur Indonesia dengan pertimbangan: (a) pertumbuhan di Wilayah Timur Indonesia memiliki potensi lebih tinggi dibandingkan dengan wilayah barat Indonesia, dan (b) dinamika logistik di wilayah timur Indonesia diharapkan bertumbuh secara eksponensial.

Peluang besar bagi Pelabuhan Bitung sebagai pelabuhan internasional dimasa mendatang, namun saat ini masih banyak hambatan dan permasalahan yang dihadapi Bitung seperti kapasitas Pelabuhan Bitung masih relatif kecil, sehingga masih membutuhkan banyak pengembangan.

Hal ini menjadi fenomena yang unik dan sangat penting untuk mengungkapkan kesiapan Pelabuhan Bitung menjadi International Hub Port, sedangkan disisi lain Pelabuhan Makassar New Port telah memiliki keunggulan dan kelebihan dalam banyak aspek untuk memberikan pelayanan kepelabuhanan yang terbaik.

International Hub Port sebagai pelabuhan internasional sebagai pengumpan dimana barang atau kargo yang akan diangkut melalui kapal-kapal jalur pelayaran luar negeri yang dikumpulkan di satu pelabuhan Indonesia. Hub port kedalaman lautnya minimal 14 meter. Jika ingin pelabuhan dikembangkan menjadi hub port maka harus dipastikan kapal segala ukuran bisa masuk dan pelayanan harus ditingkatkan. Pengembangan infrastrukturnya juga harus memenuhi persyaratan teknis kepelabuhanan seperti akses jalan raya, kereta api dan kontainer dari dan ke pelabuhan harus bisa terjamin.

\section{METODE PENELITIAN}

\section{Rancangan Penelitian}

Penelitian ini termasuk jenis penelitian penjelasan (explanatory research) berupa penelitian terapan (applied) yang bersifat dekriptif (penjelasan tanpa adanya uji-hipotesis) dengan menggunakan pendekatan kualitatif dengan fokus analisa menyusun alternatif strategi dalam perubahan lingkungan perusahaan dan alternatif strategi mana yang prioritas untuk dilaksanakan. 


\section{Situs dan Waktu Penelitian}

Lokasi atau tempat penelitian adalah kantor pusat dari PT Pelabuhan Indonesia IV (Persero) yang berkedudukan di Kota Makassar, Terminal Petikemas Makassar, Pelabuhan Makassar, Terminal Petikemas Bitung dan Pelabuhan Bitung. Secara keseluruhan waktu pelaksanaan dilaksanakan selama dua (2) bulan.

\section{Populasi dan Sampel}

Data yang dikumpulkan mencakup data primer. Data primer dikumpulkan melalui penyebaran kuesioner SWOT (lingkungan internal dan lingkungan eksternal). Unit analisis penelitian ini adalah Direksi, Kepala Biro, Senior Manajer, General Manager dan seluruh jajarannya yang bertanggung jawab atas rancangan strategis jangka panjang pada Pelabuhan Makassar dan Bitung sebanyak 30 orang.

\section{Metode Pengumpulan Data}

Pengumpulan data dalam penelitian ini dilakukan dengan 3 (tiga) cara, yaitu:

1. Studi kepustakaan, dipergunakan untuk memperoleh pengumpulan data sekunder serta untuk mendapatkan kajian dasar teoritis yang relevan dengan masalah yang diteliti

2. Studi lapangan, digunakan untuk pengumpulan data primer melalui penyebaran kuesioner untuk mengetahui persepsi responden terhadap beberapa variabel yang dipertimbangkan. Metode pengambilan sampel yang dipergunakan adalah expert survey dengan sampel yang sudah ditentukan atau dipilih secara sengaja (purpose sampling).

3. Wawancara, pengumpulan data dengan melakukan tanya jawab secara langsung dengan nara sumber agar mendapatkan informasi yang tidak terakomodasi dari kuisioner.

\section{Analisis Data}

Analisis data merupakan upaya pemecahan permasalahan penelitian untuk memperoleh jawaban atas permasalahan yang diteliti. Permasalahan dalam penelitian ini akan dianalisis menggunakan Analisis Manajemen Strategi dan Analisis Hirarki Proses (AHP).

\section{PEMBAHASAN DAN HASIL}

Identifikasi faktor kunci dari kekuatan internal yakni lokasi pelabuhan yang strategis, dukungan Penuh Manajemen PT Pelindo IV (Persero) untuk pengembangan dan pemenuhan pendanaan, kegiatan pembangunan pelabuhan sebagai International hub port telah mulai dilaksanakan, memiliki backup area pengembangan yang dapat melayani angkutan petikemas nasional dan internasional minimal 3.500.000 teus/tahun, telah melayani angkutan alih muat 


\section{Jurnal Bisnis Manajemen dan Informatika}

(transhipment) petikemas nasional dan internasional, serta Memiliki hubungan yang baik dengan para stakeholder, serikat pelabuhan, dan pemerintah daerah.

Selain terdapat kekuatan, pelabuhan juga memiliki kelemahan-kelemahan yang harus mampu diperbaiki. Berikut ini adalah hasil identifikasi kelemahan yakni adanya ketidakseimbangan cargo/inbalance cargo adanya keseimbangan antara kemajuan teknologi dan sumber daya manusia, biaya besar dan waktu yang cukup lama untuk pengembangan Pelabuhan, kegiatan promosi dan pemasaran yang dilakukan masih sangat kurang, sehingga pertumbuhan customer baru sangat kecil, serta ketergantungan terhadap vendor peralatan dan teknologi informasi yang cukup tinggi.

Lebih lanjut dilakukan analisis terkait ancaman/tantangan yang sedianya akan dihadapi oleh pelabuhan yakni Kepastian Regulasi pemerintah terhadap pengelolaan pelabuhan yang bisa berubah setiap saat, persaingan yang sangat ketat dengan berbagai pelabuhan International Hub Port di negara lain, khususnya negara tetangga yang lebih unggul dari berbagai aspek dibandingkan Pelabuhan Makassar dan Bitung, adanya konflik kepentingan antara Pemerintah Pusat dan Pemerintah Daerah terkait pengelolaan pelabuhan, tuntutan dari para stakeholder untuk terus meningkatkan kinerja pelayanan dengan biaya yang semakin murah, serta rentan terhadap perubahan teknologi transportasi laut yang sangat cepat perubahannya.

Lampiran 1 menunjukkan untuk mengetahui posisi perusahaan dalam kuadran TOWS, dilakukan perbandingan nilai faktor internal yang telah dilakukan uji validitas (kekuatan kelemahan) untuk menentukan titik pada sumbu $x$ dan perbandingan nilai faktor eksternal yang telah dilakukan uji validitas (peluang - ancaman) untuk menentukan titik pada sumbu y. Pada kuadran I tersebut, Makassar New Port dan Pelabuhan Bitung berada pada posisi yang sangat menguntungkan dimana sebuah bidang yang mempunyai peluang dan kekuatan sehingga ia dapat memanfaatkan peluang yang ada secara maksimal. Strategi yang dapat dikembangkan adalah strategi yang mendukung kebijakan pertumbuhan yang agresif, melalui pemanfataan kekuatan untuk dapat peraih peluang pasar yang cukup besar.

Lampiran 2 dalam matrik BCG terdapat empat posisi bisnis yang masing-masing. Hasil perhitungan BCG didapatkan hasil yaitu Pelabuhan Makassar dengan Pelabuhan Bitung terletak pada posisi Cash Cow. Posisi Pelabuhan Makassar memiliki pangsa pasar relatif tinggi bersaing, tetapi bersaing dalam industri yang pertumbuhannya lambat. Disebut Sapi perah karena Pelabuhan Makassar menghasilkan kas lebih dari yang dibutuhkan, mereka sering kali diperah. Banyak sapi perah saat ini adalah bintang masa lalu. Kuadran sapi perah, dalam hal ini, Pelabuhan Makassar harus dikelola untuk mempertahankan posisi kuatnya 
selama mungkin. Pada posisi ini maka strategi pengembangan jasa kepelabuhanan atau diversifikasi konsentris dapat menjadi strategi yang menarik untuk Pelabuhan Makassar yang kuat. Akan tetapi, ketika divisi sapi perah menjadi lemah, retrenchment atau diverstasi lebih sesuai untuk diterapkan di Pelabuhan Makassar.

Lampiran 3 Matriks General Electrik Pelabuhan Bitung menunjukkan bahwa Makassar New Port berada pada posisi tumbuh selektif, memliki peluang usaha untuk tumbuh karena berada pada sel yang memiliki daya tarik pasar yang besar, dengan pendapatan prioritas tinggi dan memiliki keunggulan bersaing.

Lampiran 4 menunjukkan hasil analisis preferensi menunjukkan bahwa kriteria lokasi pelabuhan 4 kali lebih penting dari kedalaman kolam, 5 kali lebih penting dari peralatan modern, 6 kali lebih penting dari ahli petikemas, 7 kali lebih penting dari lingkungan pelabuhan, dan 8 kali lebih penting dari tarif dan biaya. Kriteria kedalaman kolam 4 kali lebih penting dari peralatan modern, 5 kali lebih penting dari petikemas, 6 kali lebih penting dari lingkungan pelabuhan dan 7 kali lebih penting dari tarif dan biaya. Kriteria peralatan modern 4 kali lebih penting dari petikemas, 3 kali lebih penting dari lingkungan pelabuhan dan 2 kali lebih penting dari tarif dan biaya. Kriteria ahli petikemas 3 kali lebih penting dari lingkungan pelabuhan, dan 3 kali lebih penting dari tarif dan biaya. Kriteria lingkungan pelabuhan 2 kali lebih penting dari tarif dan biaya.

Dari hasil penelitian dengan menggunakan pendekatan model Analisis Hirarki Proses yang dilanjutkan dengan analisa data, maka hasilnya dapat disampaikan bahwa berdasarkan kriterian international hub port berdasarkan Keputusan Menteri Perhubungan Nomor KM 53 Tahun 2002 tentang Tatanan Kepelabuhanan Nasional, Makassar New Port lebih unggul dibandingkan dengan pelabuhan Bitung. Strategi yang harus dilakukan oleh Makassar New Port untuk mejadi international hub port, adalah sebagai berikut:

a. Memanfaatkan pembangunan tol laut untuk meningkatkan konektivitas ke Indonesia

Timur - Makassar, dimana Makassar merupakan bagian dari rute pelayaran utama Indonesia yang menghubungkan bagian Barat ke Timur

b. Skema pendanaan pembangunan Makassar New Port dapat dilakukan melalui investasi internal, sindikasi pembiayaan, obligasi atau kerjasama investasi.

Strategi yang daat dilakukan Pelabuhan Bitung untuk menjadi international hub port adalah sebagai berikut: 


\section{Jurnal Bisnis Manajemen dan Informatika}

a. Melakukan koordinasi dengan pemerintah, untuk mengimplementasikan KEK Bitung sebagai potensi pasar pelabuhan Bitung

b. Melakukan perencanaan pengembangan pelabuhan Bitung untuk peningkatan kapasitas terpasang.

\section{KESIMPULAN DAN SARAN}

\section{Kesimpulan}

Berdasarkan hasil Berdasarkan hasil penelitian dan pembahasan, maka dibuat simpulan sebagai berikut:

1. Berdasarkan identifikasi faktor internal dan eksternal perusahaan, dengan responden dari internal perusahaan dapat ditetapkan strategi untuk Makassar New Port dan Pelabuhan Bitung agar dapat menjadi international hub port, yaitu sebagai berikut:

a. Dengan eksistensi dan dukungan dari PT Pelindo IV (Persero) serta lokasi yang strategis memberi peluang menjadikan MNP dan pelabuhan Bitung sebagai pusat pertumbuhan industri baru yang akan mendukung terwujudnya international hub port

b. Dukungan pemerintah Daerah dan backup area yang luas, MNP dan Pelabuhan Bitung dapat dijadikan sebagai pusat konsolidasi dan distribuasi barang di wilayah Indonesia Bagian Timur

c. Melakukan pembangunan dengan pemilihan mitra strategis atau pembiayaa denga pihak ketiga

d. Melakukan pengembangan fasilitas pelabuhan sesuai dengan kapasitas dan kemampuan keuangan dengan memperhatikan pertumbuhan industri dan produksi serta konsumsi lokal3

e. Meningkatkan image dan profesionalisme Pelabuhan serta peran pelabuhan yang strategis untuk memberikan pelayanan yang optimal kepada mitra usaha serta terpercaya dari stakeholder pelabuhan untuk meningkatkan status/posisi pelabuhan

f. Melakukan koordinasi dengan stakeholder termasuk pemerintah, asosiasi dalam bidang konektivity baik sebagai transhipment maupun jalur baru dalam hal distribusi dan konsolidasi potensial komoditi

g. Membuat rencana pengembangan fasilitas dan pemetaan peluang bisnis sebagai pusat konsolidasi barang di Indonesia Bagian Timur

Dan berdasarkan analisa Quantitif Strategi Planning Matrix (QSPM), ternyata strategi VI Melakukan koordinasi dengan stakeholder termasuk pemerintah, asosiasi dalam bidang 
konektiviti baik sebagai transhipment maupun jalur baru dalam hal distribusi dan konsolidasi potensial komoditi memiliki total attractive score yang tertinggi untuk Makassar New Port dan strategi VII Membuat rencana pengembangan fasilitas dan pemetaan peluang bisnis sebagai pusat konsolidasi barang di Indonesia Bagian Timur memiliki total attractive score untintuk pelabuhan Bitung

2. Dari hasil penelitian terhadap pemangku kepentingan, dapat diketahui nilai akhir (total rangking) masing-masing kriteria international hub port, Makassar New Port berada pada jalur yang tepat sebagai internasional hub port dibandingkan dengan pelabuhan Bitung

\section{Saran}

1. Diharapkan agar pihak manajemen Makassar New Port dan Pelabuhan Bitung dapat menerjemahkan konsep strategi kepada seluruh level organisasi dengan pendekatan komunikasi yang efektif sehingga seluruh anggota organisasi dapat memahami konsep strategi tersebut dan memiliki pengetahuan dan pemahaman yang menyeluruh untuk melaksanakan strategi tersebut.

2. Pelabuhan Bitung harus dapat meminimalkan berbagai kelemahan yang dimiliki untuk mampu bersaing dengan Makasar New Port dalam menyediakan pelayanan jasa kepelabuhanan yang sesuai standar internasional, serta menjadi kawasan pertumbuhan ekonomi yang potensial di masa depan.

\section{DAFTAR PUSTAKA}

Mintzberg, H. (1998). Patterns in Strategy Formation. Management Science. 24

Perpres Nomor 26. Kebijakan Pembangunan Sistem Logistik Nasional. 2012

Undang-Undang (2008). Pelayaran Yang Berlaku Secara Efektif. Nomor 17 


\section{Jurnal Bisnis Manajemen dan Informatika}

\section{Lampiran 1. Tabel 1. Strategi kombinasi TOWS}




Lampiran 2. Tabel 2. Matriks BCG

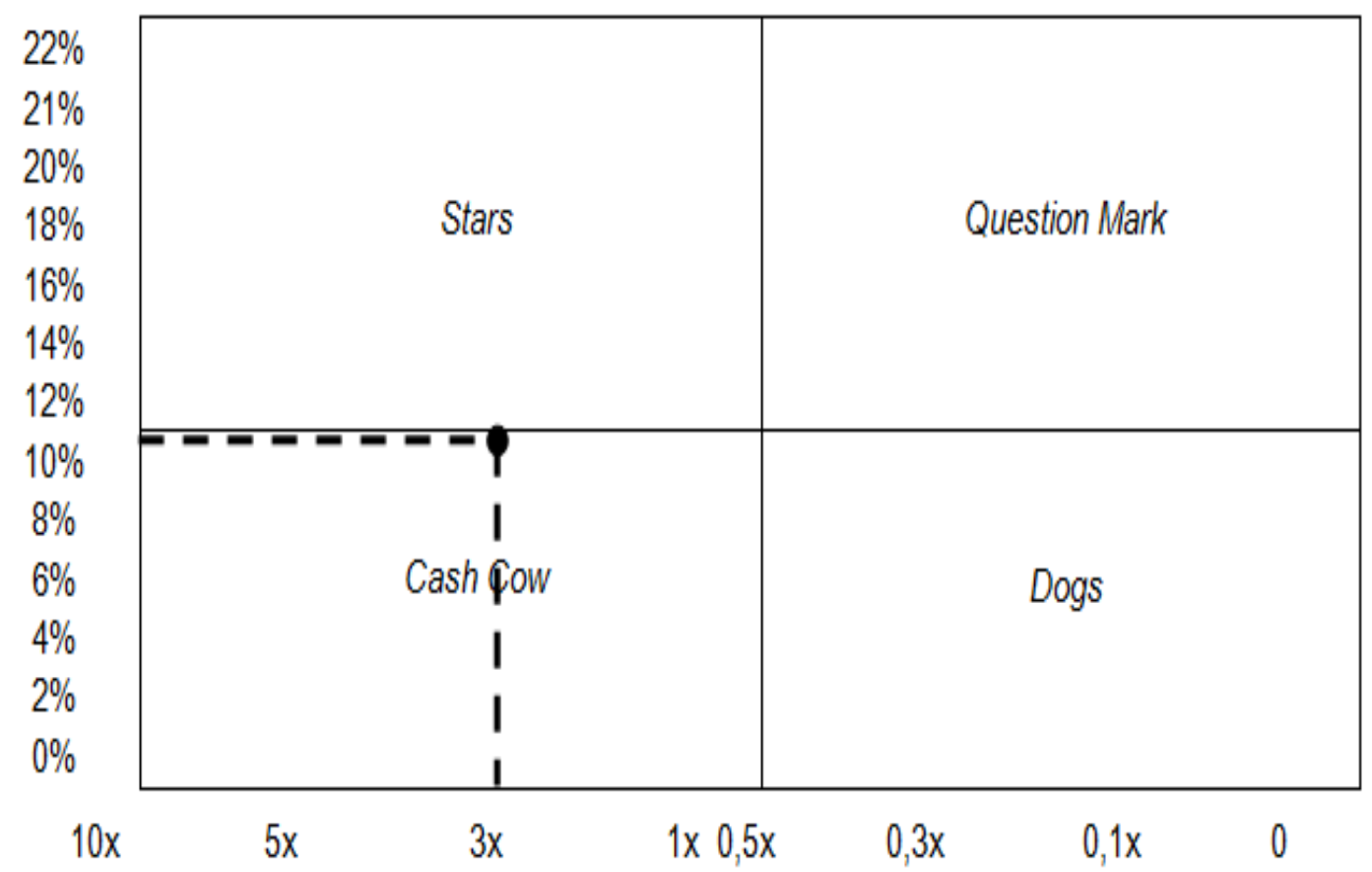

Lampiran 3. Matriks General Electrik Pelabuhan Bitung

\section{G. E. Matrix Chart}

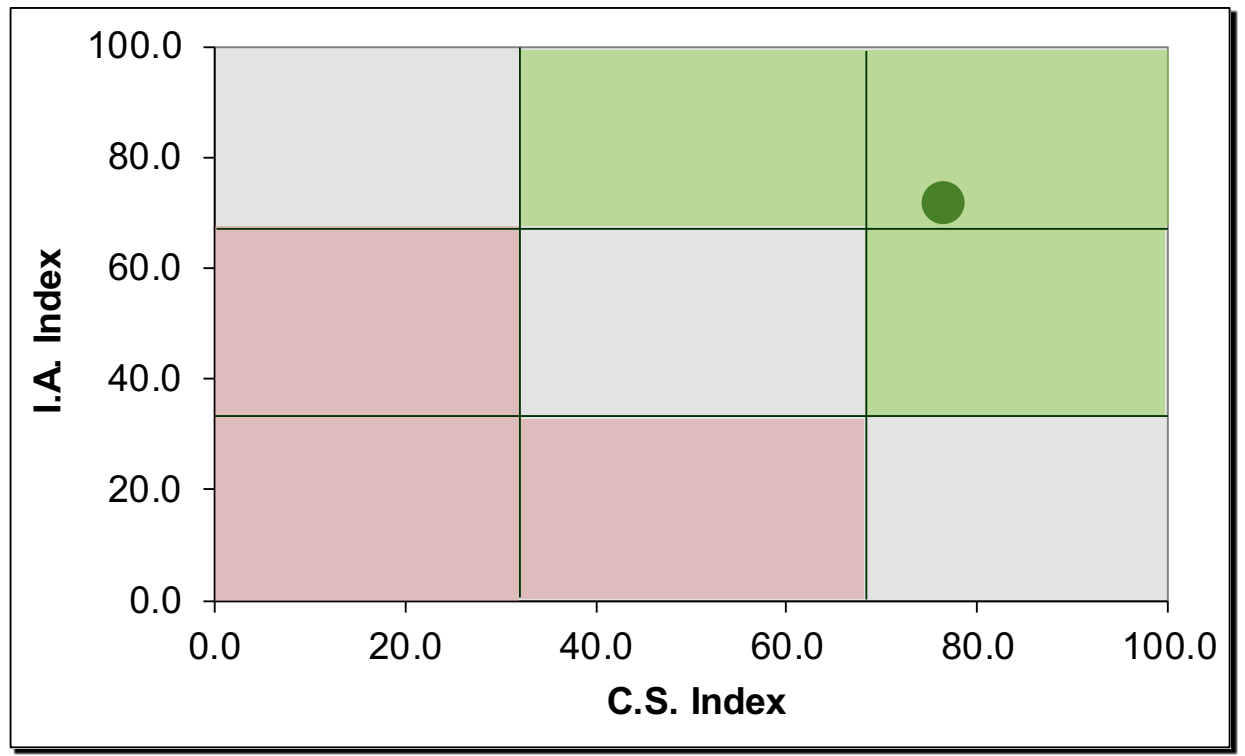


Jurnal Bisnis Manajemen dan Informatika

Lampiran 4. Matriks Faktor Pembobotan Hirarki untuk Semua Kriteria

\begin{tabular}{|c|c|c|c|c|c|c|}
\hline & $\begin{array}{c}\text { LOKASI } \\
\text { PELABUHAN }\end{array}$ & $\begin{array}{c}\text { KEDALAMA } \\
\text { N KOLAM }\end{array}$ & $\begin{array}{l}\text { PERALATAN } \\
\text { MODERN }\end{array}$ & PETIKEMAS & $\begin{array}{l}\text { LINGKUNGAN } \\
\text { PELABUHAN }\end{array}$ & $\begin{array}{l}\text { TARIF } \\
\text { DAN } \\
\text { BIAYA }\end{array}$ \\
\hline $\begin{array}{c}\text { LOKASI } \\
\text { PELABUHAN }\end{array}$ & 1 & 4 & 5 & 6 & 7 & 8 \\
\hline $\begin{array}{l}\text { KEDALAMAN } \\
\text { KOLAM }\end{array}$ & $1 / 4$ & 1 & 4 & 4 & 5 & 5 \\
\hline $\begin{array}{l}\text { PERALATAN } \\
\text { MODERN }\end{array}$ & $1 / 5$ & $1 / 3$ & 1 & 2 & 3 & 3 \\
\hline PETIKEMAS & $1 / 6$ & $1 / 4$ & $1 / 4$ & 1 & 3 & 2 \\
\hline $\begin{array}{l}\text { LINGKUNGAN } \\
\text { PELABUHAN }\end{array}$ & $1 / 7$ & $1 / 5$ & $1 / 3$ & $1 / 3$ & 1 & 2 \\
\hline $\begin{array}{l}\text { TARIF DAN } \\
\text { BIAYA }\end{array}$ & $1 / 8$ & $1 / 6$ & $1 / 2$ & $1 / 2$ & $1 / 2$ & 1 \\
\hline
\end{tabular}

Sumber: Hasil Pengolahan Data, 2017 